\title{
Influência do uso de AIB, época de coleta e tamanho de estaca na propagação vegetativa de hibisco por estaquia
}

\author{
Mariana Pizzatto ${ }^{1}$, Américo Wagner Júnior*2, Daiane Luckmann³, Kelli Pirola ${ }^{3}$ \\ Darcieli Aparecida Cassol ${ }^{3}$ Sérgio Miguel Mazaro ${ }^{2}$
}

\section{RESUMO}

A propagação vegetativa por estaquia pode ser influenciada por diversos fatores, como época de coleta, tamanho da estaca, concentração de auxinas e estado fisiológico da estaca. Como o hibisco (Hibiscus rosa-sinensis L.) é comercialmente propagado por estaquia, torna-se necessário estudar a influência de alguns desses fatores sobre a sua capacidade de enraizamento. Este trabalho teve como objetivo avaliar o efeito de concentrações de ácido indolbutírico (AIB), do tamanho da estaca e da época de realização da propagação vegetativa de hibisco por estaquia. O experimento foi conduzido no viveiro de produção de mudas, da Universidade Tecnológica Federal do Paraná (UTFPR), Campus Dois Vizinhos, em Dois Vizinhos, Paraná, Brasil. O delineamento experimental utilizado foi em blocos completamente casualizados, num fatorial 3 x 2 x 2 (concentrações de AIB x tamanho da estaca x época de propagação), com quatro parcelas e dez estacas por parcela. As estacas foram coletadas em dois períodos (junho e setembro de 2008), preparadas com tamanho de 6 e $12 \mathrm{~cm}$, e as concentrações de AIB utilizadas foram de 0; 1 e $2 \mathrm{~g} \mathrm{~L}^{-1}$. Nas duas épocas, após 77 dias, foram analisadas as percentagens de estacas enraizadas, os números de brotos vegetativos e de raízes por estaca e o comprimento das três maiores raízes por estaca. Recomenda-se que o hibisco seja propagado por estaquia em setembro, preparando-se estacas com $12 \mathrm{~cm}$ de comprimento e utilizando-se concentração de AIB de $1,6 \mathrm{~g} \mathrm{~L}^{-1}$.

Palavra-chave: propagação vegetativa, planta ornamental, Hibiscus rosa-sinensis L.

\section{ABSTRACT \\ Effects of IBA concentration, collection time and cutting length on hibiscus cutting propagation}

Vegetative propagation by tip cutting can be influenced by factors such as collection time, cutting length, auxin concentration and cutting physiological status. The ornamental Hibiscus (Hibiscus sp.) is commercially propagated by cuttings. Therefore, there is a need to study the influence of these factors on the rooting capacity of this specie. The aim of this work was to evaluate the IBA effect, cutting length and collection time on Hibiscus tip cutting propagation. The experiment was carried out in the plant production sector of the Universidade Tecnológica Federal do Paraná, Campus Dois Vizinhos, Dois Vizinhos, PR (Brazil). The experiment was arranged in a 3 x 2 x 2 factorial completely randomized block, (IBA concentration $\mathrm{x}$ cutting length $\mathrm{x}$ collection time), with four replications, with each plot consisting of ten cuts. Two collecttion times (June and September), two shoot cutting lengths (6 and $12 \mathrm{~cm})$ and three IBA concentrations $\left(0 ; 1\right.$ and $\left.2 \mathrm{~g} \mathrm{~L}^{-1}\right)$ were tested. At the two collection times, after 77 days, the rooting percentage, number

\footnotetext{
Recebido para publicação em 22/03/2010 e aprovado em 08/06/2011

${ }^{1}$ Tecnólogo em Horticultura. Universidade Estadual do Oeste do Paraná. Rua Pernambuco, 1777, CEP 85960-000, Marechal Cândido Rondon, Paraná, Brasil. mariana_pizzatto@ hotmail.com

${ }^{2}$ Engenheiros-Agrônomos, Doutores. Universidade Tecnológica Federal do Paraná - Campus Dois Vizinhos. Estrada para Boa Esperança, Km 04, caixa postal 157. CEP 85660000, Dois Vizinhos, Paraná, Brasil. e-mail: americowagner@utfpr.edu.br, sergio@utfpr.edu.br

${ }^{3}$ Tecnólogos em Horticultura, Universidade Tecnológica Federal do Paraná - Campus Pato Branco. Via do Conhecimento Km 01, CEP 85503390, Pato Branco, Paraná, Brasil. daianeluckmann@hotmail.com, kelli_pirola1@hotmail.com,so_darci@hotmail.com.
} 
of shoots and roots per cutting and the length of the three largest primary adventitious roots were evaluated. Based on the results, we can recommend the tip cutting propagation of the ornamental Hibiscus from September on, using $12 \mathrm{~cm}-$ long tip cuttings and $1,5 \mathrm{~g} \mathrm{~L}^{-1}$ IBA.

Key words: Vegetative propagation, ornamental species, Hibiscus sp.

\section{INTRODUÇÃO}

O hibisco (Hibiscus rosa-sinensis L.) é um arbusto lenhoso, originário da Ásia tropical, que pode atingir três a cinco metros de altura. Essa espécie possui grande número de variedades, com diversas formas e cores de flores. As flores são sempre solitárias, formadas no decorrer de quase todo o ano, sendo a planta normalmente cultivada isolada ou em conjunto, como cerca viva (Lorenzi, 2008).

Os métodos de propagação mais utilizados para produção de mudas dessa espécie são por enxertia, alporquia e estaquia (Lorenzi, 2008), destacando-se este último método, uma vez que possibilita a obtenção de maior número de mudas por ramo em menor espaço de tempo (Hartmann et al., 2002). A estaquia é um processo de propagação assexuada, que consiste na organização de indutores radiculares nas células do floema secundário do câmbio ou do parênquima do lenho, que se transforma em primórdios radiculares (Agustí, 2004).

O enraizamento, neste processo de propagação, é dependente de muitos fatores, tanto internos quanto externos. Dentre estes, citam-se a condição nutricional e fitossanitária da planta matriz, o potencial genético, o balanço hormonal, a época de realização, a temperatura e umidade (Hartmann et al., 2002).

A auxina é um fitorregulador endógeno, que pode ser aplicado de forma exógena, sendo responsável pelo enraizamento, como o AIA (ácido indolacético), produzido endogenamente nas regiões de crescimento, como ápice caulinar, gemas e folhas (Hinojosa, 2000). Porém, esta substância indutora da formação de raízes pode ser abundante, escassa ou mesmo ausente no interior da planta, de acordo com a condição fisiológica e genética da estaca, bem como da época do ano de propagação. Por isso, normalmente adota-se o uso de auxinas exógenas, como o ácido indolbutírico (AIB).

O uso de AIB exógeno tem como principal finalidade, acelerar o processo de enraizamento da estaca, sendo que as concentrações utilizadas variam de acordo com a época, tipo de estaca e espécie a ser propagada, existindo uma faixa considerada ótima para estimular esse processo (Wendling \& Xavier, 2005).

O tamanho das estacas está relacionado com sua condição nutricional, sendo a quantidade de reservas e o número de gemas variáveis de acordo com o comprimento utilizado. Normalmente, estacas com maior comprimento podem apresentar maior teor de carboidratos e de auxinas endógenas (Mayer et al., 2002).

O teor de carboidratos, além de ser fonte de carbono para a biossíntese de ácidos nucleicos e proteínas utilizados na produção de raízes, pode favorecer o aumento da relação $\mathrm{C} / \mathrm{N}$, que induz ao maior enraizamento (Fachinello et al., 2005). Assim, a presença de folhas e gemas nas estacas tem papel chave para a formação do novo sistema radicular, sendo responsável pela produção de assimilados e de substâncias como auxinas, sendo esta última sintetizada nesses locais (Taiz \& Zeiger, 2004).

A época de coleta das estacas está estreitamente relacionada com sua consistência, sendo que aquelas coletadas no período de crescimento vegetativo intenso (primavera/ verão) apresentam-se mais herbáceas e, de modo geral, com maior capacidade de enraizamento, em comparação com as lenhosas, que já se apresentam lignificadas (Dutra et al., 2002).

Objetivou-se, neste trabalho, avaliar o efeito da aplicação exógena de AIB, do tamanho da estaca e da época de realização da propagação vegetativa, na obtenção de plantas de hibiscos, multiplicadas por estaquia.

\section{MATERIAL E MÉTODOS}

O experimento foi conduzido no Viveiro de Produção de Mudas, da Universidade Tecnológica Federal do Paraná (UFTPR), Campus Dois Vizinhos, município de Dois Vizinhos, Paraná.

Foram utilizadas estacas lenhosas de hibisco provenientes de plantas adultas, de flores vermelhas e folhas variegadas, pertencentes ao jardim da Universidade. Os ramos, após serem retirados das plantas, foram colocados em baldes com água, evitando-se sua desidratação e oxidação, até o momento da implantação do experimento.

O delineamento experimental utilizado foi em blocos completamente casualizados, num esquema fatorial $3 \times 2 \times$ 2 (Concentração de AIB x Tamanho da Estaca x Época de coleta), com quatro parcelas e dez estacas por parcela.

As estacas foram coletadas em dois períodos (junho e setembro de 2008), preparadas com tamanhos de 6 e 12 $\mathrm{cm}$, e as concentrações de ácido indolbutírico utilizadas 
foram de $0 ; 1$ e $2 \mathrm{~g} \mathrm{~L}^{-1}$. Os dados das temperaturas médias, máximas e mínimas de cada época foram obtidos na estação meteorológica da UTFPR, Campus Dois Vizinhos.

Antes da imersão em AIB, todas as estacas sofreram duas lesões superficiais na parte basal, em lados opostos, retirando-se uma porção da casca com cerca de 0,5 $\mathrm{cm}$ de largura por 2,5 cm de extensão. Em todas as estacas, foram mantidas metade das duas folhas apicais e o seu diâmetro médio foi de $0,9 \mathrm{~mm}$.

No preparo da solução, o AIB foi dissolvido em álcool etílico absoluto (90\%), sendo, posteriormente, diluído em água destilada até a concentração desejada. As aplicações dessas soluções de AIB foram realizadas por imersão rápida (5 segundos) da base das estacas.

Após, as estacas lenhosas foram enterradas, verticalmente, até $1 / 3$ de seu comprimento, em canteiro (1,5 x 1,0 $\mathrm{m})$, contendo areia grossa granulada como substrato. No canteiro de areia, foi utilizada uma estrutura de mini-estufa com filme plástico $(150 \mu \mathrm{m})$ como cobertura na forma de túnel baixo, sendo realizadas irrigações diárias em dois turnos (manhã e tarde).

Após 77 dias, foram analisadas as percentagens de estacas enraizadas, os números de brotos vegetativos e de raízes, por estaca, e o comprimento das três maiores raízes, por estaca.

Os dados foram submetidos à análise de variância e ao teste de Tukey $(\mathrm{P} \leq 0,05)$, para o fator qualitativo, e à análise de regressão, para os fatores quantitativos, sendo os dados das percentagens de estacas enraizadas transformados em arco seno $\sqrt{\mathrm{x} / 100}$ e o do número de brotos vegetativos e de raízes em $\sqrt{x+1}$. Foi utilizado o aplicativo computacional SANEST (Zonta \& Machado, 1984).

\section{RESULTADOS E DISCUSSÃO}

Houve interação tripla significativa apenas para o comprimento das três maiores raízes. Para a percentagem de enraizamento houve interação entre os fatores tamanho da estaca e época de coleta e efeito significativo da concentração de AIB. Para o número de raízes, não houve interação entre os fatores, mas todos foram significativos isoladamente. Para o número de brotações apenas houve efeito do fator tamanho da estaca (Tabela 1).

Para as épocas de coleta em junho e setembro, os maiores comprimentos de raízes $(4,0$ e $6,25 \mathrm{~cm}$ e 5,49 e $9,46 \mathrm{~cm}$, respectivamente) nas concentrações de AIB de 0 e $1 \mathrm{~g} \mathrm{~L}^{-1}$ foram obtidos, utilizando-se estacas com $12 \mathrm{~cm}$ de comprimento. A mesma superioridade das estacas com esse comprimento $(12 \mathrm{~cm})$ foi observada na época de coleta em setembro quando aplicado $2 \mathrm{~g} \mathrm{~L}^{-1}$ de AIB (Tabela 2). Estes resultados sugerem que as estacas de $12 \mathrm{~cm}$ possuíam maior quantidade de reservas nutritivas, importantes pelo suporte metabólico e responsáveis pelo maior desenvolvimento e crescimento das raízes (Fachinello et al., 2005).

Porém, para a época de coleta de junho, o comprimento das três maiores raízes de estacas, com tamanho de 12 $\mathrm{cm}$, foi semelhante estatisticamente àquelas com $6 \mathrm{~cm}$, nas concentração de $2 \mathrm{~g} \mathrm{~L}^{-1}$ de AIB (Tabela 2).

$\mathrm{Na}$ época de coleta em junho, as temperaturas apresentaram valores médios, máximos e mínimos de 16,63; 17,20 e $16,05^{\circ} \mathrm{C}$, respectivamente. Já na época de coleta em setembro, as temperaturas foram de 20,13; 20,80 e $19,45^{\circ} \mathrm{C}$, para as médias, máximas e mínimas, respectivamente. Com isso, a época de coleta de junho foi um período de temperaturas mais baixas, em comparação com a época de coleta em setembro, o que faz com que a atividade metabólica das estacas seja baixa e o crescimento radicular seja menor, o que explica esta não diferenciação estatística entre as estacas com tamanhos de 6 e $12 \mathrm{~cm}$.

De acordo com Taiz \& Zeiger (2004), a temperatura tem efeito direto sobre o metabolismo da planta, sendo que, quanto maior, mais aceleradas serão as reações químicas, o que pode ter favorecido o desenvolvimento radicular. Segundo Hartmann et al. (2002), sob condições apropriadas (alta umidade e calor), o enraizamento de estacas é fácil e atinge altas percentagens.

Fachinello et al. (2005) informaram que o aumento da temperatura favorece a divisão celular nas estacas. Com isso, supõe-se que a maior temperatura, obtida na época de coleta em setembro, favoreceu o maior comprimento de raízes.

Ao analisar o tamanho das estacas, de acordo com a concentração de AIB testada, verificaram-se as maiores médias de crescimento radicial nas estacas de 6 e de 12 $\mathrm{cm}$, para as épocas de coleta em junho e em setembro (3,93 e 5,09 cm e, 9,46 e 9,34 cm), com uso de 1 e $2 \mathrm{~g} \mathrm{~L}^{-1}$ de AIB, respectivamente (Tabela 2).

De acordo com Xavier et al. (2009), a aplicação exógena de auxinas na base das estacas favorece a promoção mais rápida da iniciação de raízes adventícias. Neste sentido, acredita-se que o fato de o AIB induzir mais rapidamente à rizogênese tenha favorecido a obtenção dos maiores comprimentos de raízes das estacas.

Para as estacas de $6 \mathrm{~cm}$, na época de coleta em setembro, e de $12 \mathrm{~cm}$, para época de coleta em junho, o uso de AIB não influenciou estatisticamente o maior desenvolvimento radicular (Tabela 2). Os resultados obtidos para a época de coleta em setembro podem ter relação com a falta de reservas necessárias para sintetizar compostos químicos que permitam o alongamento radicular, o mesmo ocorrendo para época de coleta em junho. Para esta, acredita-se, porém, que a baixa temperatura interferiu nos processos metabólicos.

Quando se compararam estacas de 6 e $12 \mathrm{~cm}$, observou-se superioridade para esta última, em ambas 
as épocas de realização do experimento, com valores superiores a $93 \%$ de enraizamento (Tabela 3 ). Possivelmente, esses resultados estejam relacionados com a quantidade de reservas presentes nas estacas com maior comprimento. Fachinello et al. (2005) observaram que a real importância dos carboidratos para formação de raízes é que a auxina requer fonte de carbono para a biossíntese de ácidos nucleicos e proteínas, levando à necessidade de energia e carbono para formação das raízes.

Quando foram utilizadas estacas de $6 \mathrm{~cm}$, o melhor período para submetê-las ao enraizamento foi na época de coleta em junho, em comparação com a época de coleta em setembro, o mesmo não sendo observado para as estacas de $12 \mathrm{~cm}$, uma vez que, para esse comprimento, em ambas as épocas, os resultados não diferiram significativamente entre si (Tabela 3 ).

O maior enraizamento obtido com a época de coleta, em junho, para estacas de $6 \mathrm{~cm}$, pode estar relacionado com a condição hídrica das estacas, um vez que a época de coleta em setembro correspondeu a um período de temperatura mais elevada, fazendo que a estaca perdesse facilmente água por transpiração, podendo o deslocamento das auxinas endógenas até a base ter sido prejudicado pelo menor conteúdo de água.

Como a estaca de $6 \mathrm{~cm}$ apresenta menor conteúdo hídrico, se comparada com a de $12 \mathrm{~cm}$, supõe-se que, as perdas de água, resultantes da maior transpiração na época de coleta em setembro, para esta última, não comprometeram seu enraizamento, fazendo com que ambas as épocas fossem semelhantes estatisticamente entre si.

Verificou-se superioridade, em relação às das estacas de $6 \mathrm{~cm}$, para as variáveis número de raízes e número de brotações, quando foram utilizadas estacas com $12 \mathrm{~cm}$ de comprimento (Tabela 4). Nas estacas de $6 \mathrm{~cm}$ houve menor número de brotações vegetativas, evidenciando que sua fonte de carboidratos já era menor, em comparação com a das estacas maiores, de $12 \mathrm{~cm}$.

Tabela 1. Análise de variância da percentagem de enraizamento, número de raiz e brotações e do comprimento das três maiores raízes de estacas de hibisco de acordo com a concentração de AIB, tamanho de estaca e época do ano

\begin{tabular}{|c|c|c|c|c|c|}
\hline \multirow[t]{2}{*}{ Causas da variação } & \multirow[t]{2}{*}{ GL } & Enraizamento (\%) & Número de raízes & $\begin{array}{c}\text { Número de } \\
\text { brotações }\end{array}$ & $\begin{array}{l}\text { Comprimento das } 3 \\
\text { maiores raízes }(\mathrm{cm})\end{array}$ \\
\hline & & Quadrado médio & Quadrado médio & Quadrado médio & Quadrado médio \\
\hline Bloco & 3 & & & & \\
\hline Tamanho de estaca (A) & 1 & $7901,95 * *$ & $7,57 * *$ & $1,11 * *$ & $88,21 * *$ \\
\hline Concentração AIB (B) & 2 & $750,32 * *$ & $1,89 * *$ & $0,04 \mathrm{~ns}$ & $23,40 * *$ \\
\hline Época do ano $(\mathrm{C})$ & 1 & $48,82 \mathrm{~ns}$ & $6,70 * *$ & $0,03 \mathrm{~ns}$ & $57,31 * *$ \\
\hline $\mathrm{A} * \mathrm{~B}$ & 2 & $80,84 \mathrm{~ns}$ & $0,46 \mathrm{~ns}$ & $0,03 \mathrm{~ns}$ & $2,02 \mathrm{~ns}$ \\
\hline $\mathrm{A} * \mathrm{C}$ & 1 & $587,71 *$ & $0,21 \mathrm{~ns}$ & $0,007 \mathrm{~ns}$ & $16,23 * *$ \\
\hline $\mathrm{B} * \mathrm{C}$ & 2 & $185,56 \mathrm{~ns}$ & $0,02 \mathrm{~ns}$ & $0,009 \mathrm{~ns}$ & $0,49 \mathrm{~ns}$ \\
\hline $\mathrm{A} * \mathrm{~B} * \mathrm{C}$ & 2 & $24,35 \mathrm{~ns}$ & $0,005 \mathrm{~ns}$ & $0,06 \mathrm{~ns}$ & $6,72 * *$ \\
\hline Resíduo & 33 & 112,43 & 0,15 & 0,04 & 1,53 \\
\hline Total & 47 & & & & \\
\hline $\mathrm{CV}(\%)$ & & 16,37 & 16,34 & 11,88 & 23,25 \\
\hline
\end{tabular}

ns - não significativo; *, ** - significativo a $\mathrm{P}=0,05$ e 0,01 , respectivamente.

Tabela 2. Comprimento das três maiores raízes de estacas de hibisco, de acordo com a concentração de AIB, tamanho de estaca e época de coleta

\begin{tabular}{|c|c|c|c|c|}
\hline \multirow{2}{*}{ Época de coleta } & \multirow{2}{*}{ Tamanho da estaca } & \multicolumn{3}{|c|}{ Concentração de AIB (g L L } \\
\hline & & $\mathbf{0}$ & 1,0 & 2,0 \\
\hline \multirow[t]{2}{*}{ Junho } & $6 \mathrm{~cm}$ & 1,35 b B (b) & 3,93 b A (a) & 5,09 a A (a) \\
\hline & $12 \mathrm{~cm}$ & 4,00 a A (b) & 5,49 a A (b) & 5,52 a A (b) \\
\hline \multirow{2}{*}{ Setembro } & $6 \mathrm{~cm}$ & 4,27 b A (a) & 3,96 b A (a) & 5,52 b A (a) \\
\hline & $12 \mathrm{~cm}$ & 6,25 a B (a) & 9,46 a A (a) & 9,34 a A (a) \\
\hline
\end{tabular}

Médias seguidas por letras minúsculas distintas na coluna diferem entre si pelo teste de Tukey a 5\% de probabilidade para o fator época, dentro de cada comprimento de estaca.

Médias seguidas por letras maiúsculas distintas na linha diferem entre si pelo teste de Tukey a 5\% de probabilidade.

Médias entre parênteses seguidas por letras minúsculas distintas na coluna diferem entre si pelo teste de Tukey a 5\% de probabilidade, para o fator época de coleta, dentro de cada concentração de AIB.

Rev. Ceres, Viçosa, v. 58, n.4, p. 487-492, jul/ago, 2011 
Isso sugere que, pelo fato de as estacas $(12 \mathrm{~cm})$ possuírem maior conteúdo de carboidratos de reserva, também ocorre a sua maior utilização na formação do sistema radicular e na brotação das gemas da parte aérea.

De acordo com Okoro \& Grace (1978), durante o período de enraizamento, a citocinina é gradualmente metabolizada em favor da brotação e crescimento das raízes latentes ou, simplesmente, inativada pelo tecido da planta, se não houver reservas suficientes para seu metabolismo. Resultados semelhantes foram obtidos por Biasi \& Costa (2003), na estaquia lenhosa de Lippia alba (Mill.) N.E. Br. ex Britton \& P. Wilson, e por Costa et al. (2000), na de Vernonia condensata Baker, em que o aumento do comprimento da estaca proporcionou os melhores resultados nas variáveis analisadas (percentagem de enraizamento e de brotação, massas da matéria fresca e seca de raízes e de brotos e comprimento dos brotos).

Quanto à época de realização do experimento, verificou-se que as médias do número de raízes obtidas em setembro foram maiores do que em junho (Tabela 5). A influência da época de coleta das estacas no enraizamento

Tabela 3. Percentual de estacas de hibisco enraizadas de acordo com o tamanho de estaca e época de coleta

\begin{tabular}{lcc}
\hline \multirow{2}{*}{ Época de coleta } & \multicolumn{2}{c}{ Tamanho da estaca $(\mathbf{c m})$} \\
\cline { 2 - 3 } & $\mathbf{6}$ & $\mathbf{1 2}$ \\
\hline Junho & 69,47 a B & 93,41 a A \\
Setembro & 54,26 b B & 97,05 a A \\
\hline CV $(\%)$ & \multicolumn{3}{c}{16,37} \\
\hline
\end{tabular}

Letras minúsculas na coluna e maiúsculas na linha diferem entre si pelo teste de Tukey a $5 \%$ de probabilidade.

Tabela 4. Números de brotos vegetativos e de raízes de acordo com o tamanho de estaca de hibisco

\begin{tabular}{lcc}
\hline Tamanho & $\begin{array}{c}\text { Número de brotos } \\
\text { vegetativos }\end{array}$ & $\begin{array}{c}\text { Número } \\
\text { de raízes }\end{array}$ \\
\hline $6 \mathrm{~cm}$ & $1,36 \mathrm{~b}$ & $2,79 \mathrm{~b}$ \\
$12 \mathrm{~cm}$ & $2,38 \mathrm{a}$ & $6,52 \mathrm{a}$ \\
\hline $\mathrm{CV}(\%)$ & 11,88 & 16,34
\end{tabular}

Letras minúsculas na coluna diferem entre si pelo teste de Tukey a $5 \%$ de probabilidade.

Tabela 5. Número de brotos vegetativos e de raízes por estaca de acordo com a época de coleta

\begin{tabular}{lcc}
\hline Época de coleta & $\begin{array}{c}\text { Número de brotos } \\
\text { vegetativos }\end{array}$ & $\begin{array}{c}\text { Número } \\
\text { de raízes }\end{array}$ \\
\hline Junho & $1,93 \mathrm{~ns}$ & $2,88 \mathrm{~b}$ \\
Setembro & 1,76 & $6,39 \mathrm{a}$ \\
\hline $\mathrm{CV}(\%)$ & 11,88 & 16,34 \\
\hline ns - não significativo. & &
\end{tabular}

Letras minúsculas na coluna diferem entre si pelo teste de Tukey a $5 \%$ de probabilidade. de hibiscos pode ser atribuída às condições específicas de temperatura, conforme já ressaltado.

As concentrações de AIB mostraram-se significativas para as percentagens de estacas enraizadas (Figura 1A), número de raízes (Figura 1B) e comprimento das três maiores raízes (Tabela 2). O mesmo efeito não foi obtido para número de brotos (Figura 1C).

Observou-se comportamento quadrático para percentagem de estacas enraizadas, com ponto de máxima calculado para 1,61 $\mathrm{g} \mathrm{L}^{-1}$ de AIB, obtendo-se 95,60\% de enraizamento, ao mesmo tempo em que foi verificada queda no percentual de estacas enraizadas após atingir o ponto de máxima (Figura 1A). Fachinello et al. (2005) informaram que o aumento da concentração de auxina
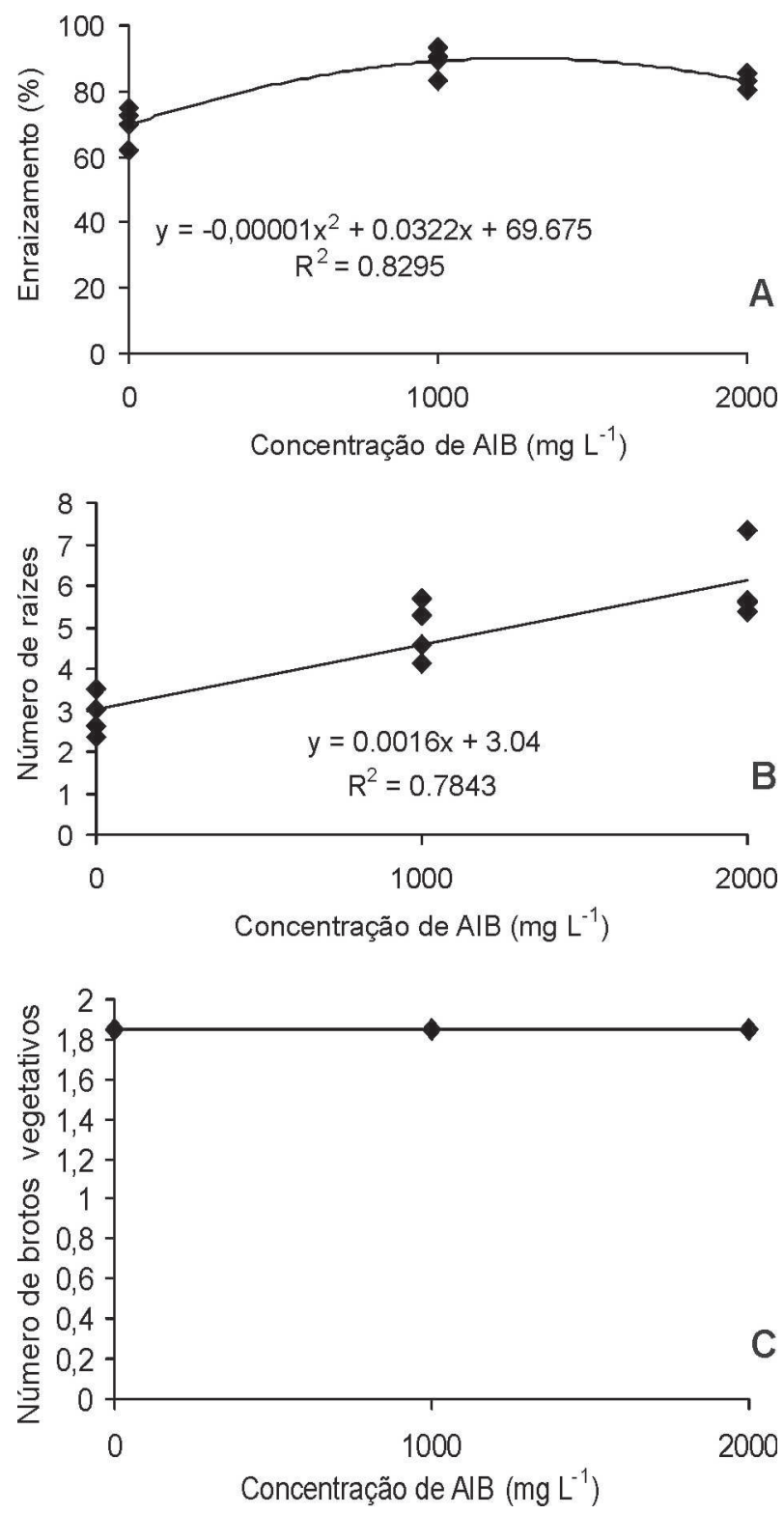

Figura 1. Enraizamento (A), número de raízes (B) e número de brotos vegetativos (C) de acordo com a concentração de AIB utilizada em estacas de hibisco.

Rev. Ceres, Viçosa, v. 58, n.4, p. 487-492, jul/ago, 2011 
exógena, aplicada em estacas, provoca efeito estimulador de enraizamento adventício até certo valor máximo, a partir do qual qualquer acréscimo no teor desse fitorregulador tem efeito inibitório, o que estaria de acordo com os resultados obtidos neste trabalho.

Por outro lado, segundo Silva et al. (2004), o uso de altas concentrações pode matar a base da estaca, causando excessiva proliferação de células, intensa calosidade ou inibição do crescimento de raízes e da parte aérea.

É importante destacar também que, quando não foram aplicadas concentrações exógenas de AIB, pôde-se obter percentagens acima de $70 \%$ de enraizamento. Supõe-se, por isso, que as estacas de hibiscos produzem quantidades suficientes de auxinas endógenas, que permitem esse alto percentual de enraizamento, podendo a espécie ser classificada como de fácil propagação vegetativa.

Quanto as raízes, pode-se observar que obteve-se maior número das mesmas com o aumento na concentração de AIB (Figura 1B). Este fato pode estar relacionado ao papel deste fitoregulador na rizogênese adventícia, uma vez que faz com que o processo ocorra de maneira mais acelerada favorecendo para o surgimento de maior número de raízes de forma mais rápida, o que não ocorreu com a concentração de $0 \mathrm{~g} \mathrm{~L}^{-1}$.

\section{CONCLUSÕES}

A propagação de hibiscos (Hibiscus rosa-sinensis) via estaquia é beneficiada quando realizada em setembro, com estacas de $12 \mathrm{~cm}$ e com uso de AIB na concentração de $1,6 \mathrm{~g} \mathrm{~L}^{-1}$.

\section{REFERÊNCIAS}

Agustí M (2004) Fruticultura. Madrid, Ediciones Mundi-Prensa. 493p.

Biasi LA \& Costa G (2003) Propagação vegetativa de Lippia alba. Ciência Rural, 33:455-459.

Costa LCB, Filho LAA \& Moreira RCT (2000) Comprimento de estacas de alumã para propagação vegetativa. In: 40a Congresso Brasileiro de Olericultura, $2^{\circ}$ Congresso Íbero-Americano sobre a utilização de plástico na Agricultura, $1^{\circ}$ Simpósio de Latino-Americano de Produção de Plantas Medicinais, Aromáticas e Condimentares. São Pedro. Brasília. CD-ROM.

Dutra LF, Kersten E \& Fachinello JC (2002) Época de coleta, ácido indolbutírico e triptofano no enraizamento de estacas de pessegueiro. Scientia Agrícola, 59:327-333.

Fachinello JC, Hoffmann A \& Nachtigal JC (2005) Propagação de plantas frutíferas. Brasília, Embrapa Informação Tecnológica. 221p.

Hartmann HT, Kester DE, Davies Junior FT \& Geneve RL (2002) Plant propagation: principles and practices. $7^{\mathrm{a}}$ ed. New Jersey, Prentice Hall. 880p.

Hinojosa GF (2000) Auxinas. In: Cid LPB (Ed) Introdução aos hormônios vegetais. Brasília, EMBRAPA. p.15-54

Lorenzi H (2008) Plantas ornamentais no Brasil: arbustivas, herbáceas e trepadeiras. $4^{\mathrm{a}}$ ed. Nova Odessa, Instituto Plantarum. 1130 p.

Mayer NA, Pereira FM \& Nachtigal JC (2002) Efeito do comprimento de estacas herbáceas de dois clones de umezeiro (Prunus mume Sieb \& Zucc.) no enraizamento adventício. Revista Brasileira de Fruticultura, 24:500-504.
Okoro OO \& Grace J (1978) The physiology of rooting populus cuttings. II. Cytokinin activity in leafless hardwood cuttings. Physiology Plantarum, 44:167-70.

Silva JM, Raposo A, Sousa JA \& Miranda EM (2004) Indução de enraizamento em estacas de joãobrandinho (Piper sp.) com ácido indolbutírico. Revista Ciência Agronômica, $35: 248-252$.

Taiz L \& Zeiger E (2004) Fisiologia vegetal. $3^{\text {a }}$ ed. Porto Alegre, Artmed. 719p.

Wendling I \& Xavier A (2005) Influência do ácido indolbutírico e da miniestaquia seriada no enraizamento e vigor de miniestacas de clones de Eucalyptus grandis. Revista Árvore, 29:921-930.

Xavier A, Wendling I \& Silva RL (2009) Silvicultura clonal: Princípios e técnicas. Viçosa, Ed. UFV. 272p.

Zonta EP \& Machado AA (1984) Sistema de análise estatística para microcomputadores: SANEST. Pelotas, UFPel. $75 \mathrm{p}$. 